\title{
Influenza- and COVID-19-Associated Pulmonary Aspergillosis: Are the Pictures Different?
}

\author{
Florian Reizine ${ }^{1, *} \mathbb{1}$, Kieran Pinceaux ${ }^{1}$, Mathieu Lederlin ${ }^{2}$, Brice Autier ${ }^{3,4}$, Hélène Guegan ${ }^{3,4}$,

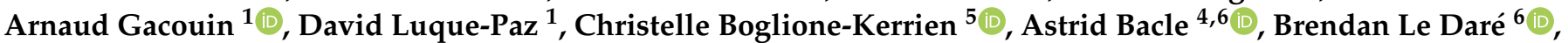 \\ Yoann Launey ${ }^{7}{ }^{(\mathbb{D}}$, Mathieu Lesouhaitier ${ }^{1}$, Benoit Painvin ${ }^{1}{ }^{\circledR}$, Christophe Camus ${ }^{1}{ }^{\mathbb{D}}$, Alexandre Mansour ${ }^{1}{ }^{(}$, \\ Florence Robert-Gangneux ${ }^{3,4}{ }^{\oplus}$, Sorya Belaz ${ }^{3}$, Yves Le Tulzo ${ }^{1}$, Jean-Marc Tadié ${ }^{1}{ }^{\oplus}$, Adel Maamar ${ }^{1}$ and \\ Jean-Pierre Gangneux ${ }^{3,4, *(\mathbb{D})}$
}

check for updates

Citation: Reizine, F.; Pinceaux, K.; Lederlin, M.; Autier, B.; Guegan, H.; Gacouin, A.; Luque-Paz, D.; Boglione-Kerrien, C.; Bacle, A.; Le Daré, B.; et al. Influenza- and COVID-19-Associated Pulmonary Aspergillosis: Are the Pictures Different? J. Fungi 2021, 7, 388. https://doi.org/10.3390/jof7050388

Academic Editor: Katrien Lagrou

Received: 14 April 2021

Accepted: 11 May 2021

Published: 15 May 2021

Publisher's Note: MDPI stays neutral with regard to jurisdictional claims in published maps and institutional affiliations.

Copyright: (c) 2021 by the authors. Licensee MDPI, Basel, Switzerland. This article is an open access article distributed under the terms and conditions of the Creative Commons Attribution (CC BY) license (https:/ / creativecommons.org/licenses/by/ $4.0 /)$.
1 CHU Rennes, Maladies Infectieuses et Réanimation Médicale, F-35033 Rennes, France; kieran.pinceaux@chu-rennes.fr (K.P.); arnaud.gacouin@chu-rennes.fr (A.G.); david.luque-paz@chu-rennes.fr (D.L.-P.); mathieu.lesouhaitier@chu-rennes.fr (M.L.); benoit.painvin@chu-rennes.fr (B.P.); christophe.camus@chu-rennes.fr (C.C.); alexandre.mansour@chu-rennes.fr (A.M.); yves.le.tulzo@chu-rennes.fr (Y.L.T.); jeanmarc.tadie@chu-rennes.fr (J.-M.T.); adel.maamar@chu-rennes.fr (A.M.)

2 CHU Rennes, Service d'Imagerie Médicale, F-35033 Rennes, France; mathieu.lederlin@chu-rennes.fr

3 CHU Rennes, Service de Parasitologie-Mycologie, F-35033 Rennes, France; brice.autier@chu-rennes.fr (B.A.); helene.guegan@chu-rennes.fr (H.G.); florence.robert-gangneux@univ-rennes1.fr (F.R.-G.); sorya.belaz@chu-rennes.fr (S.B.)

4 Univ Rennes, CHU Rennes, Inserm, EHESP, Irset (Institut de Recherche en Santé, Environnement et Travail)—UMR_S 1085, F-35000 Rennes, France; astrid.bacle@univ-rennes1.fr

5 CHU Rennes, Service de Pharmacologie, F-35033 Rennes, France; christelle.boglione-kerrien@chu-rennes.fr

6 CHU Rennes, Service de Pharmacie, F-35033 Rennes, France; brendan.le.dare@chu-rennes.fr

7 CHU Rennes, Service de Réanimation Chirurgicale, F-35033 Rennes, France; yoann.launey@chu-rennes.fr

* Correspondence: florian.reizine@chu-rennes.fr (F.R.); jean-pierre.gangneux@univ-rennes1.fr (J.-P.G.)

Abstract: Invasive pulmonary aspergillosis (IPA) in intensive care unit patients is a major concern. Influenza-associated acute respiratory distress syndrome (ARDS) and severe COVID-19 patients are both at risk of developing invasive fungal diseases. We used the new international definitions of influenza-associated pulmonary aspergillosis (IAPA) and COVID-19-associated pulmonary aspergillosis (CAPA) to compare the demographic, clinical, biological, and radiological aspects of IAPA and CAPA in a monocentric retrospective study. A total of 120 patients were included, 71 with influenza and 49 with COVID-19-associated ARDS. Among them, 27 fulfilled the newly published criteria of IPA: 17/71 IAPA (23.9\%) and 10/49 CAPA (20.4\%). Kaplan-Meier curves showed significantly higher 90-day mortality for IPA patients overall $(p=0.032)$, whereas mortality did not differ between CAPA and IAPA patients. Radiological findings showed differences between IAPA and CAPA, with a higher proportion of features suggestive of IPA during IAPA. Lastly, a wide proportion of IPA patients had low plasma voriconazole concentrations with a higher delay to reach concentrations > $2 \mathrm{mg} / \mathrm{L}$ in CAPA vs. IAPA patients $(p=0.045)$. Severe COVID-19 and influenza patients appeared very similar in terms of prevalence of IPA and outcome. The dramatic consequences on the patients' prognosis emphasize the need for a better awareness in these particular populations.

Keywords: COVID-19; influenza; pulmonary aspergillosis; CAPA; IAPA; corticosteroids; acute respiratory distress syndrome; CT-scan; voriconazole; therapeutic drug monitoring

\section{Introduction}

Invasive pulmonary aspergillosis (IPA) has been mainly described in patients with severe neutrophil dysfunction, especially those with prolonged neutropenia [1]. Increasing evidence shows that critically ill patients are at risk of IPA [2-4]. Risk factors for IPA development in these critical patients are heterogeneous. Lower respiratory tract impairment, prolonged mechanical ventilation, corticosteroid administration, or immunological 
dysfunction are often involved [2]. The diversity of the patient backgrounds is reflected by their clinical and biological presentation and thus the criteria that should be used for case definition. Generic consensus definitions, such as those of the European Organization for Research and Treatment of Cancer/Mycosis Study Group Education and Research Consortium (EORTC/MSGERC) or the AspICU [1,3,5], are sometimes not adapted to specific groups of patients [6].

Influenza-associated pulmonary aspergillosis (IAPA) is an emerging complication of influenza infection, often associated with Aspergillus tracheobronchitis [7], that markedly increases influenza-associated mortality [8]. Commonly recognized elements of IAPA include epithelial damage, NADPH-oxidase impairment and the modulation of immune function directly due to the virus, although the pathogenesis is still unclear [7]. IAPA cases exhibit atypical clinical features, which influence the results of diagnostic tests, such as broncho-alveolar lavage (BAL) and serum galactomannan (GM) or respiratory sample culture, as well as atypical radiological features [7]. This led to the recent proposition of new criteria for IAPA case definition in intensive care unit (ICU) patients [7]. Unlike IPA observed in immunocompromised patients, the radiological patterns of acute respiratory distress syndrome (ARDS) patients are much more difficult to interpret and the particularities of IPA imaging in these situations have thus far been only poorly evaluated.

The background of patients suffering from Coronavirus Disease 2019 (COVID-19) also appears to be highly compatible with the occurrence of IPA [9]. ICU patients admitted for severe acute respiratory syndrome coronavirus 2 (SARS-CoV-2) and influenza virus infections share specific features, commonly described to increase the risk for ventilator associated pneumonia [10] and particularly fungal diseases including ARDS, possible corticosteroid administration, and systemic dysregulation of immune function [11]. The incidence of COVID-19-associated pulmonary aspergillosis (CAPA) in ICU patients varies according to the major national cohorts from the United Kingdom (14.1\%), Italy (27.7\%), Germany (26.3\%), the Netherlands (19.4\%), and France (National MYCOVID clinical trial: $19.6 \%$ probable and possible CAPA) [12-16] and are similar to the rate of IAPA observed in ICU cohorts (19\%) from Belgium and the Netherlands [8]. Nevertheless, the situation appears not to be strictly transposable between the two co-infections, as, for example, Aspergillus tracheobronchitis is not commonly described in CAPA and serum GM is much less frequently positive in CAPA than IAPA [1,7]. However, a more accurate comparison between CAPA and IAPA has until recently been difficult due to the absence of a clear CAPA case definition, as highlighted by some authors [15].

The recently published CAPA case definition [17] has made it possible to compare patients suffering from IAPA and CAPA. This will improve our epidemiological knowledge concerning CAPA, which is still incomplete, and represents the first step towards improving the management of the COVID-19-associated fungal risk [18,19]. In this monocentric retrospective study, we aimed to compare the demographic, clinical, radiological, and biological features and outcomes of IAPA and CAPA cases in ICU applying the recently proposed case definitions of CAPA.

\section{Methods}

\subsection{Populations}

All patients who were admitted from 20 September 2009 to 8 February 2020 to the ICUs of the Rennes University Hospital for influenza-associated ARDS and underwent a mycological analysis of BAL, tracheal aspirate, or sputum were included in the study as "influenza patients" $(n=71)$. All patients who were admitted to the same unit for COVID-19 from 3 March to 9 September 2020 were included as "COVID-19 patients" $(n=49)$. The COVID-19 patients were strictly monitored for fungal infections twice weekly based on tracheal aspirates, as detailed in a previous publication [20]. Influenza infection and COVID-19 were confirmed by RT-PCR of respiratory samples or nasopharyngeal swabs using the Influenza A/B r-gene ${ }^{\mathrm{TM}}$ (Argene ${ }^{\circledR}$, bioMérieux, Marcy-l'Etoile, France) and TaqPath ${ }^{\mathrm{TM}}$ COVID-19 (Thermo Fisher Scientific, Illkirch-Grafenstaden, France) assays. 
ARDS was defined according to international guidelines [21]. Epidemiological and clinical data were collected during hospitalization. A blood count and biochemical check-up, including the measurement of creatinine levels, were performed at the beginning of the hospitalization for each patient. For statistical analysis, patients were classified following the AspICU [3], IAPA [7], and CAPA [17] criteria when specified. Data presented in tables and figures were extracted from each patient's medical records. The simplified acute physiology score (SAPS) II was assessed within $24 \mathrm{~h}$ following ICU admission and the Sepsis-Related Organ Failure Assessment (SOFA) score was calculated on days 1 and 5. This study conforms to the principles outlined in the Declaration of Helsinki and was approved by the institutional ethics board of Rennes University Hospital, France (N 20-56).

\subsection{Detection of Aspergillus in Respiratory Samples by Culture and PCR}

Fungal culture was performed from respiratory samples in Sabouraud-Chloramphenicol media, inoculated with $100 \mu \mathrm{L}$ of pellets, and incubated for seven days at $30^{\circ} \mathrm{C}$ and $37^{\circ} \mathrm{C}$. Aspergillus isolates were identified at the genus level based on microscopic features. Aspergillus fungi were then identified at the species level by MALDI-ToF mass spectrometry after fungal colony extraction [22] using a MALDI Biotyper device (Bruker France, Marne-la-Vallée, France) and the Mass Spectrometry Identification (MSI) database for the identification of fungi [23].

The molecular detection of Aspergillus was also performed on respiratory samples after DNA extraction. Briefly, $200 \mu \mathrm{L}$ of a BAL pellet or other liquefied respiratory samples were first incubated overnight at $56^{\circ} \mathrm{C}$ with proteinase $\mathrm{K}$ (Qiagen France, Les Ulis, France). DNA was then extracted using the manual QIAamp DNA Mini Kit (Qiagen) or the automated EZ1 Advanced XL system (Qiagen) using the EZ1 DSP Virus Kit (Qiagen). Aspergillus qPCR assays were performed as previously described, targeting either an Aspergillus mitochondrial gene or an Aspergillus 28S rDNA region [24], depending on the period of inclusion.

\subsection{Detection of Aspergillus Galactomannan (GM) in Blood and Respiratory Samples}

GM measurement was performed in serum with an index cutoff $>0.5$ and in BAL with an index cutoff $\geq 1$ using the Platelia GM Aspergillus assay (Bio-Rad, Marnes-laCoquette, France) following the manufacturer's recommendations. GM detection in nonbronchoscopic lavage respiratory samples was performed using the sōna Aspergillus lateral flow assay (LFA) (IMMY diagnostics, OK, USA), following the manufacturer's recommendations, due to the biological hazard for laboratory workers. Quantitative results were obtained by reading the LFA with the sōna cube reader (IMMY diagnostics).

\subsection{Imaging}

Chest computed tomography (CT) scans of patients who developed IPA were analyzed by a senior radiologist who was blinded to the IAPA or CAPA status. The following items were categorized as absent or present as generally reported in the literature: diffuse reticular or alveolar opacities, wedge-shaped segmental or lobar consolidation, well-circumscribed nodules, halo signs, cavitation, air crescent signs, tree in bud, bronchial wall thickening, and pleural effusion $[1,3,7]$.

\subsection{Therapeutic Drug Monitoring}

Among patients treated with voriconazole, therapeutic drug monitoring was performed after the initiation of this treatment. A plasmatic voriconazole trough concentration (VTC) target between 2 and $6 \mathrm{mg} / \mathrm{L}$ was recommended as a voriconazole therapeutic range in ICU IPA patients [25].

Trough concentrations (=Cmin), defined as concentrations measured $12 \pm 2 \mathrm{~h}$ after voriconazole administration, were measured from day 3 after the beginning of the treatment, after achievement of steady-state. Blood samples were centrifuged at $3200 \times g$ for $10 \mathrm{~min}$, and then stored at $-20^{\circ} \mathrm{C}$ prior to being assayed. Voriconazole plasma concentra- 
tions were determined using a validated liquid chromatography tandem mass spectrometry assay. The linearity range of the assay extends from 0.1 to $12 \mathrm{mg} / \mathrm{L}$.

\subsection{Statistical Analysis}

Demographic and clinical characteristics of patients are presented as numbers and percentages for categorical variables and medians and interquartile ranges (IQR, 25-75\%) for continuous variables. The Mann-Whitney U test was used for quantitative data and qualitative data were compared using the Chi-square or Fisher test, as appropriate. Survival curves were constructed until day 90 from the diagnosis of ARDS using the Kaplan-Meier method and were compared using the log rank test. Two-sided tests were performed and reached statistical significance when the $p$-value was $<0.05$.

All statistical analyses were performed using GraphPad Prism 8.4 (GraphPad Software, La Jolla, CA, USA) and R Statistical Software 3.5.2 (R Foundation for Statistical Computing, Vienna, Austria).

\section{Results}

Overall, 120 patients were included in the study, 71 admitted for severe influenza and 49 for severe COVID-19. Among them, 27 (22.5\%) presented with COVID-19- (CAPA) and Influenza- (IAPA) associated pulmonary aspergillosis. Among the 10/49 (20.4\%) CAPA patients, four were probable CAPA and six possible CAPA according to the most recent consensual definitions by Koehler et al. [17]. Among the 17/71 (23.9\%) IAPA patients, 13 fulfilled the definitions by Verweij et al. [7] and four the definitions by Blot et al. [3]. A comparative analysis of these two groups of IAPA patients showed no significant differences in terms of background, severity, or outcome. Thus, we considered all 17 patients to constitute the same IAPA group during this study. The IAPA diagnosis was based on at least one positive GM result for the serum $(n=7 / 17,41.1 \%)$ and/or BAL ( $n=10 / 17$ patients, $58.8 \%)$ and /or a fungal culture of $A$. fumigatus from respiratory samples $(n=15 / 17,88.2 \%)$. The CAPA diagnosis was based on at least one positive GM result for serum $(n=3 / 10,30 \%)$ and / or an A. fumigatus-positive culture from a non-bronchoscopic lavage $(n=9 / 10$ patients, $90 \%$ ) and/or combined positivity of GM and A. fumigatus PCR in non-bronchoscopic lavage $(n=1 / 10,10 \%)$. Mycological arguments that allowed the IPA classification are presented for each patient in Table S1.

Demographic and admission characteristics of the patients according to their aspergillosis status are summarized in Table 1 . The median age was 59 years and $80(66 \%)$ of 120 patients were men. There were no significant differences in demographic or admission characteristics between patients with and without IPA. CAPA patients were significantly older than IAPA patients (mean ages 72 and 58 years, $p=0.036$ ). The proportion of immunosuppressed patients was numerically higher among patients with IPA $(37 \%, 10 / 27)$ than those without $(20 \%, 19 / 93)$, but the difference did not reach statistical significance $(p=0.076)$. Similarly, the frequency of immunosuppressed patients was lower among CAPA patients $(20 \%)$ than IAPA patients $(47.1 \%)$ without reaching statistical difference. Among recognized risk factors for IPA, solid cancers and hematological malignancies were observed for $25.9 \%$ of IPA patients and $12.9 \%$ of patients without IPA $(p=0.13)$. A summary of reported cases is presented in Table S2. The frequency of patients with neoplasia was lower in CAPA (10\%) than IAPA patients (35.3\%), without reaching statistical difference.

The biological data at ICU admission are summarized in Table 1 and show that the CAPA patients were globally less severely ill than the IAPA patients. The SOFA score on day 1 was significantly lower for CAPA than IAPA patients $(p=0.012)$. Survival analysis at day 90 showed higher mortality among all IPA patients $(p=0.042)$, whereas mortality did not differ between those with CAPA and IAPA (Figure 1). 
Table 1. Characteristics of patients according to aspergillosis status.

\begin{tabular}{|c|c|c|c|c|c|c|c|}
\hline & $\begin{array}{l}\text { All Patients } \\
(n=120)\end{array}$ & $\begin{array}{c}\text { All } \\
\text { Aspergillosis } \\
\text { Patients }(n=27)\end{array}$ & $\begin{array}{c}\text { Non } \\
\text { Aspergillosis } \\
\text { Patients }(n=93)\end{array}$ & $p$ Value & $\begin{array}{c}\text { IAPA } \\
(n=17)\end{array}$ & $\begin{array}{c}\text { CAPA } \\
(n=10)\end{array}$ & $p$ Value \\
\hline \multicolumn{8}{|c|}{ Baseline characteristics } \\
\hline Age (years) & $59(52-67)$ & $60(52-69)$ & $59(52-67)$ & 0.54 & $58(52-63)$ & $72(57-77)$ & 0.036 \\
\hline Male sex & $80(66.4 \%)$ & $17(63 \%)$ & $63(67.7 \%)$ & 0.21 & $11(64.7 \%)$ & $6(60.0 \%)$ & $>0.99$ \\
\hline Current smoking & $31(26 \%)$ & $10(37 \%)$ & $21(22.6 \%)$ & 0.13 & $9(52.9 \%)$ & $1(10.0 \%)$ & 0.12 \\
\hline Obesity & $20(16.6 \%)$ & $4(15.4 \%)$ & $30(32.3 \%)$ & 0.09 & $3(17.6 \%)$ & $1(10.0 \%)$ & $>0.99$ \\
\hline Diabetes & $33(27.5 \%)$ & $4(14.8 \%)$ & $29(31.2 \%)$ & 0.14 & $2(11.8 \%)$ & $2(20.0 \%)$ & 0.61 \\
\hline Alcoholism & $20(16.6 \%)$ & $6(22.2 \%)$ & $14(15.1 \%)$ & 0.39 & $5(29.4 \%)$ & $1(10.0 \%)$ & 0.36 \\
\hline \multicolumn{8}{|l|}{ Immunodepression } \\
\hline $\begin{array}{l}\text { (including } \\
\text { neoplasia) }\end{array}$ & $29(24.1 \%)$ & $10(37 \%)$ & $19(20.4 \%)$ & 0.12 & $8(47.1 \%)$ & $2(20.0 \%)$ & 0.23 \\
\hline Neoplasia & $19(15.8 \%)$ & $7(25.9 \%)$ & $12(12.9 \%)$ & 0.13 & $6(35.3 \%)$ & $1(10.0 \%)$ & 0.2 \\
\hline - Solid cancer & $3(2.5 \%)$ & $1(3.7 \%)$ & $2(2.2 \%)$ & 0.53 & $1(5.9 \%)$ & $0(0.0 \%)$ & $>0.99$ \\
\hline$-\mathrm{HM}$ & $16(13.3 \%)$ & $6(22.2 \%)$ & $10(10.7 \%)$ & 0.19 & $5(29.4 \%)$ & $1(10.0 \%)$ & 0.36 \\
\hline $\begin{array}{l}\text { Chronic } \\
\text { obstructive } \\
\text { pulmonary } \\
\text { disease }\end{array}$ & $17(14.2 \%)$ & $6(22.2 \%)$ & $11(11.8 \%)$ & 0.17 & $6(35.3 \%)$ & $0(0.0 \%)$ & 0.057 \\
\hline $\begin{array}{c}\text { Chronic kidney } \\
\text { disease }\end{array}$ & $10(8.3 \%)$ & $2(7.4 \%)$ & $8(8.6 \%)$ & $>0.99$ & $1(5.9 \%)$ & $1(10.0 \%)$ & $>0.99$ \\
\hline Cirrhosis & $8(6.7 \%)$ & $4(14.8 \%)$ & $4(4.3 \%)$ & 0.07 & $4(23.5 \%)$ & $0(0.0 \%)$ & 0.26 \\
\hline \multicolumn{8}{|l|}{ ARDS etiology } \\
\hline $\begin{array}{l}\text { - Influenza } \\
\text { - COVID-19 }\end{array}$ & $\begin{array}{l}71(59.2 \%) \\
49(40.8 \%)\end{array}$ & $\begin{array}{l}17(63 \%) \\
10(37 \%)\end{array}$ & $\begin{array}{l}54(58.1 \%) \\
39(41.9 \%)\end{array}$ & 0.65 & NA & NA & NA \\
\hline \multicolumn{8}{|c|}{ Clinical and biological admission ICU data } \\
\hline $\begin{array}{l}\text { Neutrophil } \\
\left(10^{9} / \mathrm{L}\right)\end{array}$ & $6.9(3.9-11.4)$ & $8.2(3.8-13.2)$ & $6.9(4.1-11)$ & 0.67 & $\begin{array}{c}8.0 \\
(3.6-17.7)\end{array}$ & $\begin{array}{c}8.5 \\
(4.1-11.0)\end{array}$ & 0.72 \\
\hline $\begin{array}{c}\text { Lymphocyte } \\
\left(10^{9} / \mathrm{L}\right)\end{array}$ & $0.56(0.32-0.87)$ & $0.54(0.36-0.72)$ & $0.59(0.32-0.93)$ & 0.44 & $\begin{array}{c}0.38 \\
(0.29-0.55)\end{array}$ & $\begin{array}{c}0.83 \\
(0.72-0.92)\end{array}$ & $<0.0001$ \\
\hline $\begin{array}{l}\text { Ratio of } \mathrm{PaO} 2 \text { to } \\
\mathrm{FiO} 2 \text { on day } 1\end{array}$ & $98(67-147)$ & $98(74-143)$ & $105(67-148)$ & 0.96 & 86 (69-98) & $\begin{array}{c}143 \\
(109-154)\end{array}$ & 0.01 \\
\hline $\begin{array}{l}\text { SAPS II score on } \\
\text { day } 1\end{array}$ & $44(35-61)$ & $48(36-64)$ & $43(34-60)$ & 0.22 & $58(42-64)$ & $40(34-68)$ & 0.48 \\
\hline $\begin{array}{l}\text { SOFA score on } \\
\text { day } 1\end{array}$ & $8(5-10)$ & $9(5-12)$ & $7(4-10)$ & 0.19 & $10(7-13)$ & $5(2-8)$ & 0.012 \\
\hline \multicolumn{8}{|c|}{ Clinical course data } \\
\hline \multirow{2}{*}{$\begin{array}{c}\text { Duration of } \\
\text { mechanical } \\
\text { ventilation (days) } \\
\text { ECMO }\end{array}$} & $18(11-27)$ & $23(17-40)$ & $17(9-25)$ & 0.038 & $23(16-49)$ & $23(19-30)$ & 0.56 \\
\hline & $45(37.5 \%)$ & $13(48.1 \%)$ & $32(34.4 \%)$ & 0.19 & $12(70.6 \%)$ & $1(10.0 \%)$ & 0.004 \\
\hline $\begin{array}{l}\text { SOFA score on } \\
\text { day } 5\end{array}$ & $8(6-12)$ & $11(7-14)$ & $7(5-11)$ & 0.003 & $10(6-14)$ & $12(8-13)$ & 0.83 \\
\hline \multirow{2}{*}{$\begin{array}{c}\text { RRT use } \\
\text { Corticosteroids } \\
\text { use }\end{array}$} & $37(30.8 \%)$ & $13(48.1 \%)$ & $24(25.8 \%)$ & 0.027 & $8(47.1 \%)$ & $5(50.0 \%)$ & $>0.99$ \\
\hline & $55(45.8 \%)$ & $19(70.4 \%)$ & $36(38.7 \%)$ & 0.004 & $12(70.6 \%)$ & $7(70.0 \%)$ & $>0.99$ \\
\hline \multirow{2}{*}{$\begin{array}{c}\text { - before day } 7 \\
\text { - after day } 7 \\
\text { ICU length of stay } \\
\text { (days) }\end{array}$} & $\begin{array}{l}45(81.8 \%) \\
10(18.2 \%)\end{array}$ & $\begin{array}{l}16(84.2 \%) \\
3(15.8 \%)\end{array}$ & $\begin{array}{l}29(80.6 \%) \\
7(19.4 \%)\end{array}$ & $\begin{array}{c}0.008 \\
0.14\end{array}$ & $\begin{array}{c}12(100 \%) \\
0(0.0 \%)\end{array}$ & $\begin{array}{l}4(57.1 \%) \\
3(42.9 \%)\end{array}$ & $\begin{array}{l}0.22 \\
0.04\end{array}$ \\
\hline & $22(12-33)$ & $25(19-48)$ & $19(12-30)$ & 0.044 & $29(12-48)$ & $24(22-29)$ & 0.97 \\
\hline Death in the ICU & $28(23.3 \%)$ & $9(33.3 \%)$ & $19(20.4 \%)$ & 0.16 & $6(35.3 \%)$ & $3(30.0 \%)$ & $>0.99$ \\
\hline 90-day survival & $89(74.2 \%)$ & $16(59.3 \%)$ & $74(79.6 \%)$ & 0.032 & $9(52.9 \%)$ & $7(70.0 \%)$ & 0.44 \\
\hline Death in hospital & $31(25.8 \%)$ & $12(44.4 \%)$ & $19(20.4 \%)$ & 0.012 & $8(47.1 \%)$ & $4(40.0 \%)$ & 0.45 \\
\hline
\end{tabular}

Data are presented as medians (IQR: interquartiles) or $n$ (\%). $p$ values comparing the invasive aspergillosis vs. no aspergillosis groups and IAPA vs. CAPA were calculated using Mann-Whitney (continuous variables) and Fisher or Chi2 tests when appropriate (categorical variables). AKI: acute kidney injury, PaO2: arterial oxygen partial pressure, SAPS II: Simplified Acute Physiology Score I, SOFA: Sequential Organ Failure Assessment, HM: hematological malignancies, COVID-19: Coronavirus Disease 2019, ECMO: extracorporeal membrane oxygenation; $\mathrm{PaO} 2$ : arterial oxygen tension; FiO2: fraction of inspired oxygen; RRT: renal replacement therapy; ICU: intensive care unit; among neoplasia. 

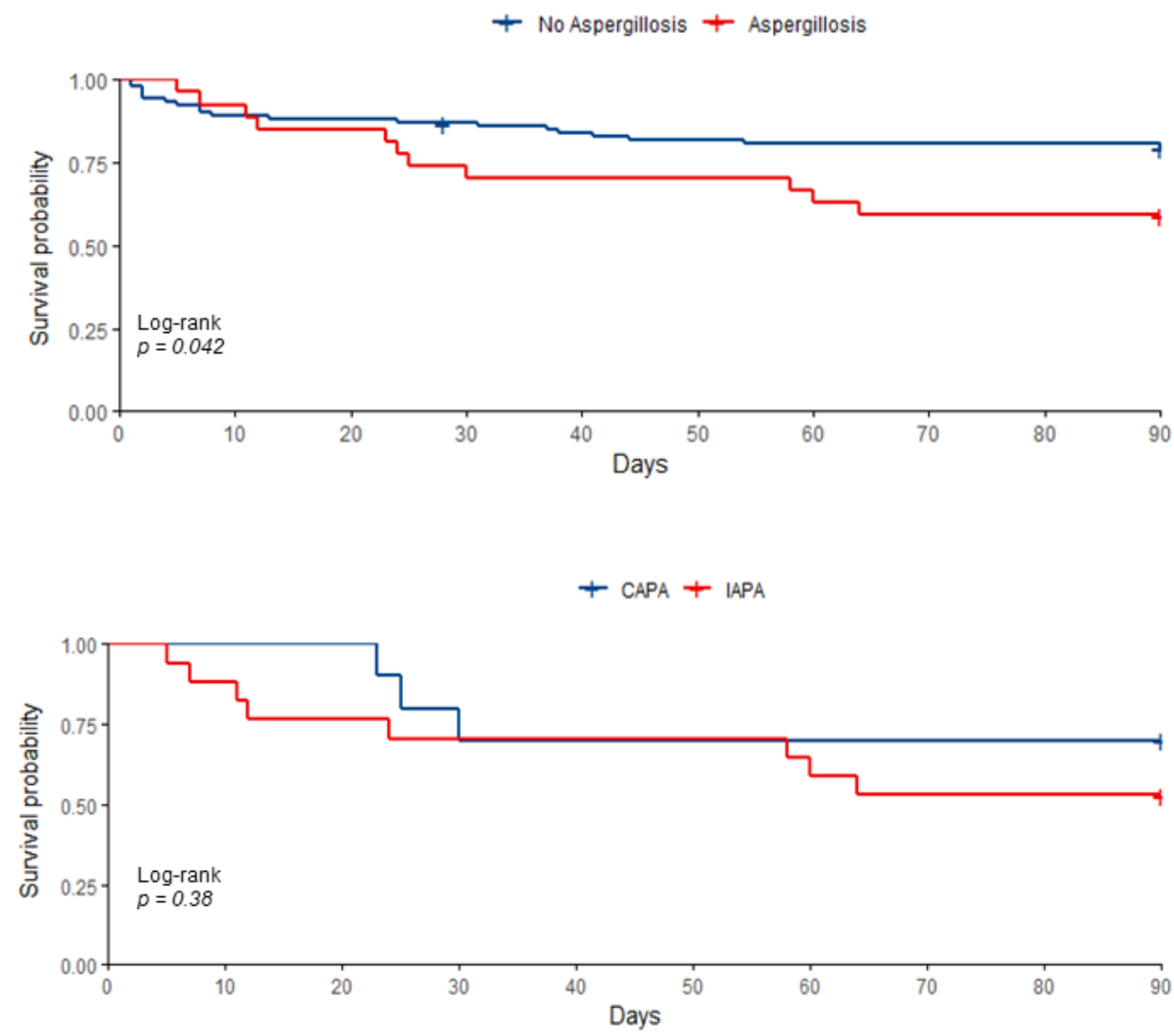

Figure 1. Cumulative 90-day mortality from admission to the intensive care unit in the whole population (Top) and among CAPA and IAPA patients (Below).

In this cohort, the duration of mechanical ventilation was higher for patients with IPA (23 days [IQR 17-40] than those without (17 days [IQR 9-25], $p=0.038$ ) (Table 1). Renal replacement therapy was more frequent for IPA patients $(p=0.027)$ and supportive therapy by extracorporeal membrane oxygenation (ECMO) was less frequent for CAPA than IAPA patients $(p=0.004)$. Patients who developed IPA were more frequently treated by corticosteroids $(70.4 \%$ vs. $38.7 \%, p=0.004)$ and the frequency of such treatment was similar for the CAPA and IAPA groups. The median ICU length of stay was longer for IPA patients (25 days [IQR 19-48] vs. 19 days [IQR 12-30], $p=0.04$ ). Finally, survival at 90 days after ICU admission was 59.3\% for those with IPA and 79.6\% for those without an Aspergillus infection $(p=0.032)$. Assessment of clinical and laboratory features at IPA diagnosis is presented in Table 2. Of note, a trend pointing towards a longer median interval between ICU admission and IPA diagnosis in CAPA (6 days [IQR 3-13]) was observed compared to IAPA patients (3 days [IQR 2-5]; $p=0.14$ ). Among patients treated by voriconazole, CAPA patients experienced a trend towards a longer time to reach therapeutic range (VTC target: 2-6 mg/L) (7 days [IQR 6-32] vs. 4 days [2-8], $p=0.096)$. Therapeutic drug monitoring of these patients showed a higher proportion of CAPA patients that obtained a delayed voriconazole therapeutic range since at day 5 after the initiation of voriconazole, $83.3 \%$ of CAPA patients and $33.3 \%$ of IAPA patients remained with a voriconazole dosage under $2 \mathrm{mg} / \mathrm{L}(p=0.045)$. Similarly VTC appeared to be lower in CAPA patients $(2.2 \mathrm{mg} / \mathrm{L}$ [IQR $1.1-4.4]$ vs. $3.9 \mathrm{mg} / \mathrm{L}$ [IQR 2-5.7]; $p=0.01)$. 
Table 2. Clinical and biological characteristics at CAPA and IAPA diagnosis.

\begin{tabular}{|c|c|c|c|c|}
\hline & $\begin{array}{l}\text { All Aspergillosis } \\
\text { Patients }(n=27)\end{array}$ & IAPA $(n=17)$ & CAPA $(n=10)$ & $p$ Value \\
\hline Temperature $\left({ }^{\circ} \mathrm{C}\right)$ & $38.2(38.0-39.0)$ & $38.0(37.8-38.8)$ & $38.9(38.1-39.0)$ & 0.19 \\
\hline Systolic pressure (mmHg) & $92(81-102)$ & $92(85-102)$ & $90(78-101)$ & 0.95 \\
\hline Neutrophil count $\left(10^{9} / \mathrm{L}\right)$ & $9.6(4.5-16.5)$ & $13.2(5.5-19.5)$ & $7.6(4.0-10.3)$ & 0.18 \\
\hline Lymphocyte count $\left(10^{9} / \mathrm{L}\right)$ & $0.72(0.51-1.03)$ & $0.80(0.50-1.22)$ & $0.72(0.55-0.80)$ & 0.56 \\
\hline Ratio of $\mathrm{PaO} 2$ to $\mathrm{FiO} 2$ & $134(102-179)$ & $108(86-165)$ & $162(147-208)$ & 0.04 \\
\hline Septic shock & $17(63.0 \%)$ & $12(70.6 \%)$ & $5(50.0 \%)$ & 0.41 \\
\hline Need for vasopressors & $19(70.4 \%)$ & $12(70.6 \%)$ & $7(70.0 \%)$ & $>0.99$ \\
\hline $\begin{array}{l}\text { Delay between admission and aspergillosis } \\
\text { onset (days) }\end{array}$ & $4(2-8)$ & $3(2-5)$ & $6(3-13)$ & 0.14 \\
\hline $\begin{array}{l}\text { Mechanical ventilation duration after } \\
\text { aspergillosis onset (days) }\end{array}$ & $20(9-36)$ & $22(8-46)$ & $17(11-23)$ & 0.64 \\
\hline Antifungal therapy & $25(92.6 \%)$ & $17(100 \%)$ & $8(80 \%)$ & 0.13 \\
\hline Time to VCZ therapeutic range (days) * & $6(4-9)$ & $4(2-8)$ & $7(6-32)$ & 0.096 \\
\hline Delayed VCZ therapeutic range ( $>5$ days) * & $9 / 18(50 \%)$ & $4 / 12(33.3 \%)$ & $5 / 6(83.3 \%)$ & 0.045 \\
\hline $\operatorname{VTC}(\mathrm{mg} / \mathrm{L}) *$ & $2.8(1.5-5)$ & $3.9(2-5.7)$ & $2.2(1.1-4.4)$ & 0.01 \\
\hline $\operatorname{VTC} \min (\mathrm{mg} / \mathrm{L})$ * & $1.6(0.5-3.8)$ & $3.5(1-5)$ & $0.8(0.2-0.8)$ & 0.038 \\
\hline $\mathrm{VTC} \max (\mathrm{mg} / \mathrm{L}) *$ & $5.8(4.5-7.2)$ & $6.1(5.4-7.6)$ & $5.2(3-7)$ & 0.23 \\
\hline Antifungal treatment duration (days) & $42(14-42)$ & $17(14-47)$ & $42(37-42)$ & 0.49 \\
\hline
\end{tabular}

Data are presented as medians (IQR: interquartiles) or $n(\%) . p$ values comparing IAPA vs. CAPA were calculated using Mann-Whitney (continuous variables) and Fisher or Chi2 tests when appropriate (categorical variables). IAPA: Influenza Associated Pulmonary Aspergillosis; CAPA: COVID-19 Associated Pulmonary Aspergillosis; PaO2: arterial oxygen partial pressure; FiO2: Fraction of inspired Oxygen; VCZ: Voriconazole; VTC: Voriconazole Trough Concentration. * Among IPA patients, 19 were treated by voriconazole alone and 18 of them were performed a watchful therapeutic drug monitoring, two patients were treated by isavuconazole, two others by voriconazole which was switched for isavuconazole, one by voriconazole plus amphotericin B, and finally two patients did not receive any antifungal treatment. The data concerning TDM monitoring displayed in this table are based on the results of the 18 patients who only received voriconazole and for whom frequent monitoring could be performed.

Chest CT scans were performed for 24 of 27 patients between eight days before and 12 days after IPA diagnosis. Lung parenchyma abnormalities were present in all patients (Table 3). A lower proportion of well-circumscribed nodules, tree-in bud, and bronchial wall thickening was observed for CAPA than IAPA patients $(0 \%$ vs. $42.9 \%$ [ $p=0.024]$ for well-circumscribed nodules, $0 \%$ vs. $50 \%$ [ $p=0.014]$ for tree in bud, and $10 \%$ vs. $57 \%$ [ $p=0.03$ ] for bronchial wall thickening). These different aspects are presented in Figure 2 and the comparison of CT-scan features of CAPA patients at admission and at diagnosis is presented in Table S3.

Table 3. CT-scan analysis of IAPA and CAPA patients.

\begin{tabular}{|c|c|c|c|c|}
\hline & $\begin{array}{l}\text { All Aspergillosis } \\
\text { Patients }(n=24)\end{array}$ & IAPA $(n=14)$ & CAPA $(n=10)$ & $p$ Value \\
\hline Delay between ICU admission and CT scan & $10(4-15)$ & $9(4-15)$ & $10(3-15)$ & 0.99 \\
\hline Delay between IPA diagnosis and CT scan & $5(0-9)$ & $4(0-9)$ & $7(0-9)$ & 0.75 \\
\hline Diffuse reticular or alveolar opacities & $24(100 \%)$ & $14(100 \%)$ & $10(100 \%)$ & 0.99 \\
\hline $\begin{array}{l}\text { Wedge-shaped segmental or lobar } \\
\text { consolidation }\end{array}$ & $17(70.8 \%)$ & $10(71.4 \%)$ & $7(70.0 \%)$ & 0.99 \\
\hline Well-circumscribed nodule(s) & $6(25.0 \%)$ & $6(42.9 \%)$ & $0(0.0 \%)$ & 0.024 \\
\hline Halo sign & $3(12.5 \%)$ & $2(14.3 \%)$ & $1(10.0 \%)$ & 0.68 \\
\hline Cavitation & $5(20.8 \%)$ & $5(35.7 \%)$ & $0(0.0 \%)$ & 0.053 \\
\hline Air-crescent sign & $0(0.0 \%)$ & $0(0.0 \%)$ & $0(0.0 \%)$ & 0.99 \\
\hline Tree in bud & $7(29.2 \%)$ & $7(50.0 \%)$ & $0(0.0 \%)$ & 0.019 \\
\hline Bronchial wall thickening & $8(33.3 \%)$ & $8(57.1 \%)$ & $1(10.0 \%)$ & 0.03 \\
\hline Pleural effusion & $9(37.5 \%)$ & $5(35.7 \%)$ & $4(40.0 \%)$ & 0.99 \\
\hline
\end{tabular}

Data are presented as $n(\%) . p$ values comparing influenza associated pulmonary aspergillosis (IAPA) vs. COVID-19 associated pulmonary aspergillosis (CAPA). IAPA and CAPA groups were tested using Fisher's exact test (categorical variables). CT-scan: computerizedtomography scanner. 

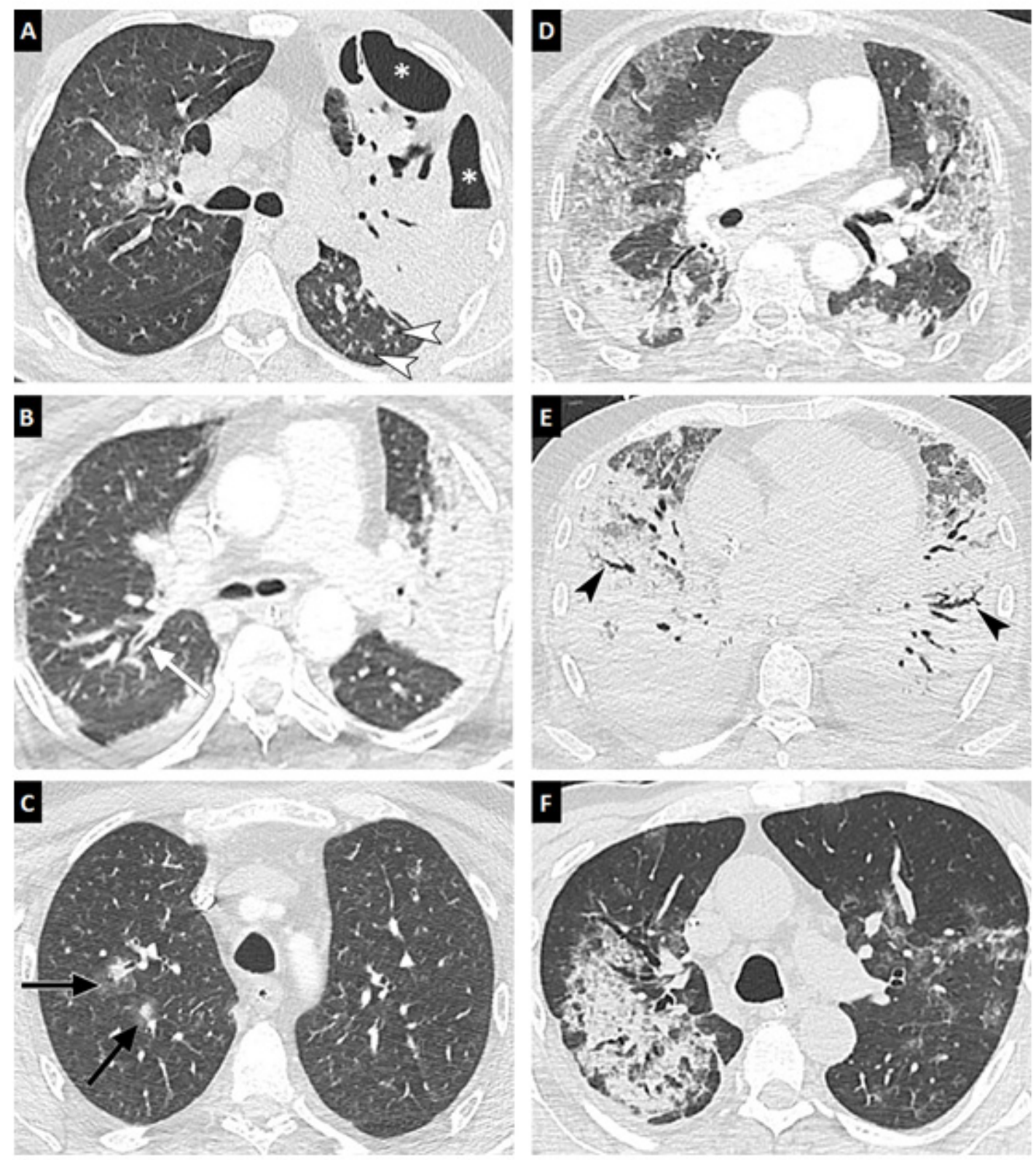

Figure 2. Chest CT-scan of LAPA and CAPA patients. Chest CT scans in the axial plane (lung window: W1600/L-500 HU) of three patients with LAPA (A-C) and three patients with CAPA (D-F). Typical CT findings in LAPA are unilateral or bilateral areas of consolidation with air bronchogram (A,B), cavity formation (asterisks), tree in bud (white arrowheads), bronchial wall thickening (white arrow), or occasionally nodules with halo signs (C, black arrows). Patients with CAPA may exhibit non-specific CT findings, such as bilateral areas of ground-glass opacity and/or crazy paving (D), extensive consolidations areas associated with peripheral traction bronchiectasis (E, black arrowheads), or, more rarely, unilateral consolidation areas (F). Despite not being very specific for a SARS COV2 infection, findings observed in $(\mathbf{D}, \mathbf{E})$ pictures can be seen frequently in severe COVID-19 patients.

Finally, a summary of similarities and differences between CAPA and IAPA are presented in Table 4. 
Table 4. Summary of similarities and differences between CAPA and IAPA.

\begin{tabular}{lll}
\hline \multicolumn{1}{c}{ Similarities between CAPA and IAPA } & \multicolumn{1}{c}{ Differences between CAPA and IAPA } \\
\hline - $\quad \begin{array}{l}\text { Prevalence of IPA between COVID-19 and } \\
\text { influenza-associated ARDS }\end{array}$ & $\bullet$ & Higher proportion of older patients among CAPA patients \\
Background of patients & $\bullet$ & Higher ratio of PaO2 to FiO2 in CAPA patients \\
- Similar clinical courses in ICU with a trend for a longer & $\bullet$ & Lower proportion of ECMO among CAPA patients \\
median interval between ICU admission and IPA & $\bullet$ & $\begin{array}{l}\text { Therapeutic drug monitoring of voriconazole more } \\
\text { challenging for CAPA patients }\end{array}$ \\
diagnosis in CAPA & $\begin{array}{l}\text { Lower proportion of patients presenting radiological } \\
\text { Higher mortality than for patients without IPA among } \\
\text { both CAPA and IAPA patients }\end{array}$ & features suggestive of IPA among CAPA patients \\
\hline
\end{tabular}

\section{Discussion}

In this single-center study, $22.5 \%$ of patients admitted to the ICU for a severe viral infection, such as COVID-19 (20.4\%) or Influenza pneumonia (23.9\%), developed IPA. A similar prevalence of IPA in ICU patients was observed in the two major representative series of severe influenza (19.2\% in a Dutch-Belgian multicenter study on 432 patients, [8]) and COVID-19 patients (19.6\% probable and possible CAPA in a French multicenter prospective study with 509 patients included [16]). Secondary fungal infections may have had an impact on the prognosis for these patients, as the mortality rate, duration of mechanical ventilation, and ICU length of stay were associated with the occurrence of IPA. To date, only limited data are available on the comparison of IAPA and CAPA. In-hospital death occurred for $47.1 \%$ and $40 \%$ of patients with IAPA and CAPA, respectively, vs. $20.4 \%$ for patients without aspergillosis. Such a high mortality rate has already been observed for IAPA vs. non IAPA ICU patients (51\% vs. 28\%, respectively, [26]). Bartoletti et al., among others, have reported similar mortality rates of $44 \%$ for CAPA patients vs. $19 \%$ for non-CAPA patients during the COVID-19 pandemic [13]. Although the median age was significantly higher for CAPA than IAPA patients, other demographic data and characteristics of the patients at IPA diagnosis were comparable between the two populations. Among them, immunosuppression was not statistically significantly different, but $47.1 \%$ of IAPA patients were immunosuppressed vs. 20\% of CAPA patients. Concerning biological data, lymphopenia, the $\mathrm{PaO}_{2}$ to $\mathrm{FiO}_{2}$ ratio on day 1, and the SOFA score on day 1 were less severe for the CAPA than IAPA patients.

IPA diagnosis in non-neutropenic ICU patients is challenging, as the clinical and radiological features of IPA are not specific and can be affected by underlying conditions. The radiological criteria of pulmonary mold diseases were recently revised in the consensus definitions for invasive fungal disease [1]. The authors proposed to add a new more sensitive item, defined as wedge-shaped lobar or segmental consolidation, to the classical CT criteria (solid nodule, halo sign, cavitation, air-crescent sign). These updated criteria were validated in a recent cohort analysis in which nodule and/or consolidation patterns were observed in more than $98 \%$ of IPA patients, irrespective of their neutrophil status [27]. Nodule and consolidation patterns were present, alone or together, in our study in $83 \%$ of cases $(93 \%$ of IAPA and $70 \%$ of CAPA). Of note, although these updated criteria increase the sensitivity of CT for the detection of aspergillosis, they concurrently decrease its specificity, and there is currently no CT sign that is both sensitive and specific for aspergillosis. In the present study, although radiological findings were generally considered to not be suggestive of IPA during ARDS, a meticulous analysis showed several interesting differences between the images, with well-circumscribed nodules, tree in bud, and bronchial wall thickening, which were observed significantly more frequently in IAPA patients than CAPA patients. Otherwise, the timing of imaging may also affect the sensitivity of such tools regarding IPA diagnosis. It may be useful to perform new CT scans after the diagnosis of IPA in order to increase the sensitivity.

Because of these non-specific features, mycological testing is of great value for the screening of IPA in these patients. Compared to the AspICU classification, the main advance of the new consensual IAPA and CAPA definitions is to fine-tune criteria and 
tools for respiratory samples. In the IAPA definition according to Verweij et al., positive tracheal aspirates and even positive sputum cultures are criteria for probable IAPA, depending on the clinical presentation [28], and pulmonary or cavitating infiltrates [7]. Concerning CAPA, PCR and GM detection in respiratory samples are now included in the definition by Koehler et al. and although positive BAL is a criterion for probable CAPA, non-bronchoscopic respiratory samples are criteria for possible CAPA. The severity and clinical outcome of IAPA and CAPA from this series relative to that of other ICU patients highlights the relevance of these new definitions.

These specific conditions suggest that IPA is likely to be underdiagnosed in ARDS populations [4], whereas recent evidence has suggested that critically ill patients, in particular both severe influenza and COVID-19 patients, are populations at risk of IPA. Several mechanisms that may facilitate fungal infection have been identified, such as sepsis-induced systemic immunosuppression due to severe influenza virus or SARS-CoV-2 infection [29]. Several recent studies reported profound lymphopenia in severe COVID-19 associated with the expansion of myeloid derived suppressor cells, which may promote the acquisition of secondary infections, as illustrated by the large proportion of COVID-19 patients that develop respiratory reactivation of Herpes virus [30]. On the other hand, alveolar damage, dysfunction of mucociliary clearance, and local immune disorders due to COVID-19 or severe influenza pneumonia may also be key mechanisms involved in fungal invasion [8]. Finally, recent therapeutic strategies have emerged worldwide during the first months of COVID-19 pandemic with the aim of reducing inpatient mortality, such as corticosteroids, new antiviral drugs, or biotherapies. The recent RECOVERY trial [31] has positioned corticosteroids as first-line therapeutic agents, with a demonstrated improvement of patient prognosis. Although such improvement with low-dose corticosteroids (i.e., $6 \mathrm{mg}$ of dexamethasone per day for 10 days) should be highlighted, we observed a significant association between corticosteroid use and the occurrence of IPA. Cohort studies have already demonstrated that corticosteroids increase the risk of IPA in severe influenza patients [11], emphasizing the need for enhanced awareness of IPA in these patients. Drug-drug interactions also arise in this context. Dexamethasone was widely used in CAPA patients and induces CYP2C9, which could decrease the VTC [32]. Thus, therapeutic drug monitoring is a cornerstone for patient management, as we faced low concentrations of voriconazole in this series with a significant delay to reach the optimal therapeutic range in CAPA vs. IAPA patients. Since we faced difficulties reaching voriconazole therapeutic concentrations in CAPA patients, the use of alternative antifungal treatments such as isavuconazole or posaconazole could be envisaged in this specific population $[33,34]$.

Our study had several limitations, including the sample size, which prevented multivariate analysis. Furthermore, during the first wave of the COVID-19 pandemic, bronchoscopic explorations were considered as a source of exposure to SARS-CoV-2 for physicians due to the risk of the aerosolization during this procedure. Thus, we performed such investigations less frequently in COVID-19 patients; this risk has been debunked in recent papers [35]. Hence, it was not always possible to identify bronchoscopic findings suggestive of Aspergillus tracheobronchitis, such as epithelial plaques, pseudomembranes, or ulcers.

The main strengths of this study included the standardized management of ARDS and mycological testing of all patient samples, allowing an exhaustive laboratory data set. Furthermore, this is one of the first studies to apply the new consensual criteria for both IAPA and CAPA, whereas questions have been recently raised concerning the relevance of other classifications in determining the true burden of disease [6].

In conclusion, ICU patients presenting with ARDS during COVID-19 are very similar to those with severe influenza pneumonia in terms of the prevalence of IPA and outcome. It is now possible to draw the archetype of such patients using the new clinical and biological case definitions of IAPA and CAPA. Radiological findings of IPA in both populations using the new criteria increased the sensitivity but still lack specificity. Nevertheless, they also showed interesting differences between IAPA and CAPA. IAPA typically occurs earlier 
after ICU admission, in a more immunosuppressed and/or chronic respiratory disease background than CAPA, which is mainly favored by advanced age, irrespective of the medical background and with a lower rate of positivity of angioinvasion biomarkers. Finally, reaching voriconazole trough concentrations remains challenging in CAPA patients and emphasizes the importance of therapeutic drug monitoring. Future larger prospective studies may help in designing the most well-adapted personalized management to prevent IPA, which represents a high burden of death in severe COVID-19 and Influenza pneumonia.

Supplementary Materials: The following are available online at https:/ / www.mdpi.com/article/10 .3390/jof7050388/s1, Table S1: Mycological arguments for invasive pulmonary aspergillosis associated to influenza pneumonia (IAPA) and COVID-19 (CAPA) and classification, Table S2: Summary of reported cases of influenza associated pulmonary aspergillosis (IAPA) and COVID-19 associated pulmonary aspergillosis (CAPA). Table S3: Comparison of CT-scan features of CAPA petients at admission and at diagnosis.

Author Contributions: Conceptualization and design was provided by F.R., K.P., M.L. (Mathieu Lederlin), A.G., J.-M.T., A.M. (Adel Maamar), and J.-P.G. Data analysis and interpretation were carried out by F.R., K.P., B.A., H.G., D.L.-P., C.B.-K., A.B., B.L.D., Y.L. and M.L. (Mathieu Lesouhaitier), B.P., C.C., A.M. (Adel Maamar), A.M. (Alexandre Mansour), F.R.-G., S.B. and J.-P.G.; CT-scans analysis were performed by M.L. (Mathieu Lederlin); Drafting and revision of the manuscript was carried out by F.R., M.L. (Mathieu Lederlin), Y.L., Y.L.T. and J.-P.G. with all authors providing critical feedback and edits to subsequent revisions. All authors have read and agreed to the published version of the manuscript.

Funding: This research received no external funding.

Institutional Review Board Statement: This study conforms to the principles outlined in the Declaration of Helsinki and was approved by the institutional ethics board of Rennes University Hospital, France (N 20-56).

Informed Consent Statement: According to the institutional ethics board of Rennes University Hospital, France (N 20-56), a non-opposition statement was obtained for all patients included and, where applicable, relative or their legal representative, meaning that all had received written detailed information on the objectives of the study and were free to request withdrawal of their data at any time.

Data Availability Statement: Data are availbale in the Clinical data center of our hospital.

Acknowledgments: We thank the teams from the ICU and mycology laboratory of the Rennes Teaching Hospital.

Conflicts of Interest: J.-P.G. has received research grants and funding from MSD and Pfizer. The other authors report no conflict of interest related to this work.

\section{References}

1. Donnelly, J.P.; Chen, S.C.; Kauffman, C.A.; Steinbach, W.J.; Baddley, J.W.; Verweij, P.E.; Clancy, C.J.; Wingard, J.R.; Lockhart, S.R.; Groll, A.H.; et al. Revision and Update of the Consensus Definitions of Invasive Fungal Disease From the European Organization for Research and Treatment of Cancer and the Mycoses Study Group Education and Research Consortium. Clin. Infect. Dis. 2020, 71,1367-1376. [CrossRef]

2. Taccone, F.S.; Van den Abeele, A.-M.; Bulpa, P.; Misset, B.; Meersseman, W.; Cardoso, T.; Paiva, J.-A.; Blasco-Navalpotro, M.; De Laere, E.; Dimopoulos, G.; et al. Epidemiology of Invasive Aspergillosis in Critically Ill Patients: Clinical Presentation, Underlying Conditions, and Outcomes. Crit. Care 2015, 19, 7. [CrossRef]

3. Blot, S.I.; Taccone, F.S.; Van den Abeele, A.-M.; Bulpa, P.; Meersseman, W.; Brusselaers, N.; Dimopoulos, G.; Paiva, J.A.; Misset, B.; Rello, J.; et al. A Clinical Algorithm to Diagnose Invasive Pulmonary Aspergillosis in Critically Ill Patients. Am. J. Respir. Crit. Care Med. 2012, 186, 56-64. [CrossRef] [PubMed]

4. Loughlin, L.; Hellyer, T.P.; White, P.L.; McAuley, D.F.; Conway Morris, A.; Posso, R.B.; Richardson, M.D.; Denning, D.W.; Simpson, A.J.; McMullan, R. Pulmonary Aspergillosis in Patients with Suspected Ventilator-Associated Pneumonia in UK ICUs. Am. J. Respir. Crit. Care Med. 2020, 202, 1125-1132. [CrossRef] [PubMed]

5. Maertens, J.; Theunissen, K.; Verbeken, E.; Lagrou, K.; Verhaegen, J.; Boogaerts, M.; Eldere, J.V. Prospective Clinical Evaluation of Lower Cut-Offs for Galactomannan Detection in Adult Neutropenic Cancer Patients and Haematological Stem Cell Transplant Recipients. Br. J. Haematol. 2004, 126, 852-860. [CrossRef] 
6. $\quad$ Bassetti, M.; Giacobbe, D.R.; Grecchi, C.; Rebuffi, C.; Zuccaro, V.; Scudeller, L. FUNDICU investigators Performance of Existing Definitions and Tests for the Diagnosis of Invasive Aspergillosis in Critically Ill, Adult Patients: A Systematic Review with Qualitative Evidence Synthesis. J. Infect. 2020, 81, 131-146. [CrossRef]

7. Verweij, P.E.; Rijnders, B.J.A.; Brüggemann, R.J.M.; Azoulay, E.; Bassetti, M.; Blot, S.; Calandra, T.; Clancy, C.J.; Cornely, O.A.; Chiller, T.; et al. Review of Influenza-Associated Pulmonary Aspergillosis in ICU Patients and Proposal for a Case Definition: An Expert Opinion. Intensive Care Med. 2020, 46, 1524-1535. [CrossRef] [PubMed]

8. Schauwvlieghe, A.F.A.D.; Rijnders, B.J.A.; Philips, N.; Verwijs, R.; Vanderbeke, L.; Van Tienen, C.; Lagrou, K.; Verweij, P.E.; Van de Veerdonk, F.L.; Gommers, D.; et al. Invasive Aspergillosis in Patients Admitted to the Intensive Care Unit with Severe Influenza: A Retrospective Cohort Study. Lancet Respir. Med. 2018, 6, 782-792. [CrossRef]

9. Rutsaert, L.; Steinfort, N.; Van Hunsel, T.; Bomans, P.; Naesens, R.; Mertes, H.; Dits, H.; Van Regenmortel, N. COVID-19-Associated Invasive Pulmonary Aspergillosis. Ann. Intensive Care 2020, 10, 71. [CrossRef]

10. Maes, M.; Higginson, E.; Pereira-Dias, J.; Curran, M.D.; Parmar, S.; Khokhar, F.; Cuchet-Lourenço, D.; Lux, J.; Sharma-Hajela, S.; Ravenhill, B.; et al. Ventilator-Associated Pneumonia in Critically Ill Patients with COVID-19. Crit. Care 2021, 25, 25. [CrossRef]

11. Wauters, J.; Baar, I.; Meersseman, P.; Meersseman, W.; Dams, K.; De Paep, R.; Lagrou, K.; Wilmer, A.; Jorens, P.; Hermans, G. Invasive Pulmonary Aspergillosis Is a Frequent Complication of Critically Ill H1N1 Patients: A Retrospective Study. Intensive Care Med. 2012, 38, 1761-1768. [CrossRef]

12. White, P.L.; Dhillon, R.; Cordey, A.; Hughes, H.; Faggian, F.; Soni, S.; Pandey, M.; Whitaker, H.; May, A.; Morgan, M.; et al. A National Strategy to Diagnose COVID-19 Associated Invasive Fungal Disease in the ICU. Clin. Infect. Dis. 2020. [CrossRef]

13. Bartoletti, M.; Pascale, R.; Cricca, M.; Rinaldi, M.; Maccaro, A.; Bussini, L.; Fornaro, G.; Tonetti, T.; Pizzilli, G.; Francalanci, E.; et al. Epidemiology of Invasive Pulmonary Aspergillosis among COVID-19 Intubated Patients: A Prospective Study. Clin. Infect. Dis. 2020. [CrossRef] [PubMed]

14. Koehler, P.; Cornely, O.A.; Böttiger, B.W.; Dusse, F.; Eichenauer, D.A.; Fuchs, F.; Hallek, M.; Jung, N.; Klein, F.; Persigehl, T.; et al. COVID-19 Associated Pulmonary Aspergillosis. Mycoses 2020, 63, 528-534. [CrossRef]

15. van Arkel, A.L.E.; Rijpstra, T.A.; Belderbos, H.N.A.; van Wijngaarden, P.; Verweij, P.E.; Bentvelsen, R.G. COVID-19-Associated Pulmonary Aspergillosis. Am. J. Respir. Crit. Care Med. 2020, 202, 132-135. [CrossRef] [PubMed]

16. Gangneux, J.P. Characterization of fungal infections in COVID-19 infected and mechanically ventilated patients in ICU: The MYCO-VID clinical trial. In Proceedings of the Data Presented during the Réunion Interdisciplinaire de Chimiothérapie Infectieuse (RICAI Congress), Paris, France, 14-15 December 2020.

17. Koehler, P.; Bassetti, M.; Chakrabarti, A.; Chen, S.C.A.; Colombo, A.L.; Hoenigl, M.; Klimko, N.; Lass-Flörl, C.; Oladele, R.O.; Vinh, D.C.; et al. Defining and Managing COVID-19-Associated Pulmonary Aspergillosis: The 2020 ECMM/ISHAM Consensus Criteria for Research and Clinical Guidance. Lancet Infect. Dis. 2020. [CrossRef]

18. Verweij, P.E.; Gangneux, J.-P.; Bassetti, M.; Brüggemann, R.J.M.; Cornely, O.A.; Koehler, P.; Lass-Flörl, C.; van de Veerdonk, F.L.; Chakrabarti, A.; Hoenigl, M.; et al. Diagnosing COVID-19-Associated Pulmonary Aspergillosis. Lancet Microbe 2020, 1, e53-e55. [CrossRef]

19. Gangneux, J.-P.; Bougnoux, M.-E.; Dannaoui, E.; Cornet, M.; Zahar, J.R. Invasive Fungal Diseases during COVID-19: We Should Be Prepared. J. Mycol. Med. 2020, 30, 100971. [CrossRef] [PubMed]

20. Gangneux, J.-P.; Reizine, F.; Guegan, H.; Pinceaux, K.; Le Balch, P.; Prat, E.; Pelletier, R.; Belaz, S.; Le Souhaitier, M.; Le Tulzo, Y.; et al. Is the COVID-19 Pandemic a Good Time to Include Aspergillus Molecular Detection to Categorize Aspergillosis in ICU Patients? A Monocentric Experience. J. Fungi (Basel) 2020, 6, 105. [CrossRef] [PubMed]

21. ARDS Definition Task Force; Ranieri, V.M.; Rubenfeld, G.D.; Thompson, B.T.; Ferguson, N.D.; Caldwell, E.; Fan, E.; Camporota, L.; Slutsky, A.S. Acute Respiratory Distress Syndrome: The Berlin Definition. JAMA 2012, 307, 2526-2533. [CrossRef]

22. Cassagne, C.; Ranque, S.; Normand, A.-C.; Fourquet, P.; Thiebault, S.; Planard, C.; Hendrickx, M.; Piarroux, R. Mould Routine Identification in the Clinical Laboratory by Matrix-Assisted Laser Desorption Ionization Time-of-Flight Mass Spectrometry. PLoS ONE 2011, 6, e28425. [CrossRef] [PubMed]

23. Normand, A.C.; Becker, P.; Gabriel, F.; Cassagne, C.; Accoceberry, I.; Gari-Toussaint, M.; Hasseine, L.; De Geyter, D.; Pierard, D.; Surmont, I.; et al. Validation of a New Web Application for Identification of Fungi by Use of Matrix-Assisted Laser Desorption Ionization-Time of Flight Mass Spectrometry. J. Clin. Microbiol. 2017, 55, 2661-2670. [CrossRef] [PubMed]

24. Guegan, H.; Robert-Gangneux, F.; Camus, C.; Belaz, S.; Marchand, T.; Baldeyrou, M.; Gangneux, J.-P. Improving the Diagnosis of Invasive Aspergillosis by the Detection of Aspergillus in Broncho-Alveolar Lavage Fluid: Comparison of Non-Culture-Based Assays. J. Infect. 2018, 76, 196-205. [CrossRef]

25. Abdul-Aziz, M.H.; Alffenaar, J.-W.C.; Bassetti, M.; Bracht, H.; Dimopoulos, G.; Marriott, D.; Neely, M.N.; Paiva, J.-A.; Pea, F.; Sjovall, F.; et al. Antimicrobial Therapeutic Drug Monitoring in Critically Ill Adult Patients: A Position Paper. Intensive Care Med. 2020, 46, 1127-1153. [CrossRef] [PubMed]

26. Rijnders, B.J.A.; Schauwvlieghe, A.F.A.D.; Wauters, J. Influenza-Associated Pulmonary Aspergillosis: A Local or Global Lethal Combination? Clin. Infect. Dis. 2020, 71, 1764-1767. [CrossRef]

27. Herbrecht, R.; Guffroy, B.; Danion, F.; Venkatasamy, A.; Simand, C.; Ledoux, M.-P. Validation by Real-Life Data of the New Radiological Criteria of the Revised and Updated Consensus Definition for Invasive Fungal Diseases. Clin. Infect. Dis. 2020, 71, 2773-2774. [CrossRef] 
28. Nyga, R.; Maizel, J.; Nseir, S.; Chouaki, T.; Milic, I.; Roger, P.-A.; Van Grunderbeeck, N.; Lemyze, M.; Totet, A.; Castelain, S.; et al. Invasive Tracheobronchial Aspergillosis in Critically Ill Patients with Severe Influenza. A Clinical Trial. Am. J. Respir. Crit. Care Med. 2020, 202, 708-716. [CrossRef]

29. Reizine, F.; Lesouhaitier, M.; Gregoire, M.; Pinceaux, K.; Gacouin, A.; Maamar, A.; Painvin, B.; Camus, C.; Le Tulzo, Y.; Tattevin, P.; et al. SARS-CoV-2-Induced ARDS Associates with MDSC Expansion, Lymphocyte Dysfunction, and Arginine Shortage. J. Clin. Immunol. 2021, 41, 515-525. [CrossRef]

30. Le Balc'h, P.; Pinceaux, K.; Pronier, C.; Seguin, P.; Tadié, J.-M.; Reizine, F. Herpes Simplex Virus and Cytomegalovirus Reactivations among Severe COVID-19 Patients. Crit. Care 2020, 24, 530. [CrossRef]

31. RECOVERY Collaborative Group; Horby, P.; Lim, W.S.; Emberson, J.R.; Mafham, M.; Bell, J.L.; Linsell, L.; Staplin, N.; Brightling, C.; Ustianowski, A.; et al. Dexamethasone in Hospitalized Patients with Covid-19. N. Engl. J. Med. 2021, 384, 693-704. [CrossRef]

32. Imataki, O.; Yamaguchi, K.; Uemura, M.; Fukuoka, N. Voriconazole Concentration Is Inversely Correlated with Corticosteroid Usage in Immunocompromised Patients. Transpl. Infect. Dis. 2018, 20, e12886. [CrossRef]

33. Maertens, J.A.; Raad, I.I.; Marr, K.A.; Patterson, T.F.; Kontoyiannis, D.P.; Cornely, O.A.; Bow, E.J.; Rahav, G.; Neofytos, D.; Aoun, M.; et al. Isavuconazole versus Voriconazole for Primary Treatment of Invasive Mould Disease Caused by Aspergillus and Other Filamentous Fungi (SECURE): A Phase 3, Randomised-Controlled, Non-Inferiority Trial. Lancet 2016, 387, 760-769. [CrossRef]

34. Maertens, J.A.; Rahav, G.; Lee, D.-G.; Ponce-de-León, A.; Ramírez Sánchez, I.C.; Klimko, N.; Sonet, A.; Haider, S.; Diego Vélez, J.; Raad, I.; et al. Posaconazole versus Voriconazole for Primary Treatment of Invasive Aspergillosis: A Phase 3, Randomised, Controlled, Non-Inferiority Trial. Lancet 2021, 397, 499-509. [CrossRef]

35. Gao, C.A.; Bailey, J.I.; Walter, J.M.; Coleman, J.M.; Malsin, E.S.; Argento, A.C.; Prickett, M.H.; Wunderink, R.G.; Smith, S.B. NU COVID Investigators Bronchoscopy on Intubated COVID-19 Patients Is Associated with Low Infectious Risk to Operators. Ann. Am. Thorac. Soc. 2021. [CrossRef] [PubMed] 